\title{
The role of general surgery consultations in patient management
}

\author{
Şahin Kahramanca, Oskay Kaya, Cem Azılı, Hakan Güzel, Gülay Özgehan, Burak İrem
}

\section{ABSTRACT}

Clinic of General Surgery, Dışkapı Yıldırım Beyazıt Training Hospital, Ankara, Turkey

\section{Address for Correspondence Dr. Şahin Kahramanca Clinic of General Surgery, Dışkapı Yıldııım Beyazıt Training Hospital, Ankara, Turkey Phone.: +903125962314 e-mail: drkahramancasahin@gmail.com}

Received: 19.11.2012

Accepted: 04.02.2013

(C) Copyright 2013 by Turkish Surgical Association

Available online at www.ulusalcerrahidergisi.org
Objective: Consultation results of patients who were thought to require a surgical intervention and were evaluated in the General Surgery Department for diagnostic support and treatment, upon detection of pathology in clinical and/or laboratory tests.

Material and Methods: In a six-months period, 221 patients were retrospectively analyzed. There were 121 male $(54.75 \%)$ and 100 female (45.25\%) patients and the mean age was 46 years (15-102). The departments which requested consultation, the reason for consultation, test and physical examination findings before consultation, required additional tests after consultation and results of consultations were recorded as well as performed interventions.

Results: The majority of consultations were from the emergency department (91.9\%) and the most frequent reason was abdominal pain (29.9\%). No tests were performed before consultation in $21 \%$ of cases. Physical examination was completely fulfilled in $100 \%$ of judicial cases, but this ratio was $35 \%$ in perianal diseases and $30 \%$ in patients with bowel obstruction. Additional tests were required in $54.3 \%$ of the patients after consults. Out of the whole group with surgical consultation, $21 \%$ were operated under general anesthesia, $9 \%$ under local anesthesia, while an elective operation was suggested in $3 \%$.

Conclusion: Currently, it is mandatory that patient management is carried out with a multidisciplinary approach; however, we believe that consultations should be asked in a more selective manner.

Key Words: General surgery, consultation, patient management

\section{INTRODUCTION}

Consultation defines follow-up and treatment of a patient in accordance with the clinical knowledge, experience and recommendations of physicians related to the specific condition. The patient's physician in charge should evaluate medical history, perform physical examination and the necessary tests for diagnosis and should ask for a written consultation if he/she fails to diagnose or believes this pathology to require an intervention out of his/her primary interest; and the consultant doctor should transfer the knowledge and experience to the primary physician both in oral and written forms. Ethically, recommendations of the consultant physician should be followed in patient treatment $(1,2)$.

General surgery is distinctive in being the most comprehensive surgical field, interested in dealing with a wide range of diseases, from the gastrointestinal tract to the breast and endocrine system. In this study, characteristics of patients who were consulted and contribution of consultation results to the treatment were evaluated retrospectively based on patient files, in General Surgery clinics of a training and research hospital acting as a tertiary referral center.

\section{MATERIAL AND METHODS}

An ethical board approval was obtained from Diskapi Yildirim Beyazit Education and Research Hospital Ethics Committee on 17.12.2012 on 06/01 with registration number. 221 patients who were consulted to the general surgery department between January 2012-June 2012 were retrospectively evaluated. Data regarding; the clinic asking for the consultation, reasons for consultation, whether the responsible physician performed a physical examination before seeking consultation or not, requirement for additional laboratory and radiological procedures, diagnoses, the final decisions and the medical/surgical treatment types were recorded.

Patient data including age, sex, type and duration of complaints, additional laboratory, radiologic or endoscopic evaluations asked by surgeons have also been recorded.

General surgery consultations were evaluated in three groups:

1. Consultations sent from the emergency department.

2. Consultation sent from in-patient services. 
a) Consultations sent from in-patient internal medicine services.

b) Consultations sent from in-patient surgical [except general surgery] services.

c) Consultations sent from intensive care units.

3. Consultations sent from surgical services other than general surgery, for patients planned to undergo an operation by that service, to be evaluated in terms of general surgery in the preoperative period.

As a result of the consultations, patients were evaluated in four groups:

1. Patients in whom a surgical intervention was not planned,

2. Patients requiring emergency general surgical intervention and had been operated,

3. Patients not requiring urgent surgery but surgical followup,

4. Patients who were hospitalized for further follow-up and treatment, with related consultations, were examined.

\section{Statistical Analysis}

Statistical Package for the Social Sciences (SPSS) for Windows 11.5 software was used for data analysis. Calculated values were expressed as numbers and proportions.

\section{RESULTS}

During the six-month study period, the general surgery clinic was consulted for 221 patients, under three main groups. Among them, 121 were male, 100 were female, and the mean age of all patients was 46 years (15-102). This parameter was 44 years for men, and 49 years for women.

The departments asking for consultation are shown in Table 1. In order of decreasing frequency, emergency services were the service asking for consultations the most with 203 patients (91.9\%), while inpatient services were the second with 18 patients. Consultations from inpatient services were divided into three sub-groups. Six of them were from the intensive care unit $(2.7 \%), 5(2.3 \%)$ from general internal medicine clinics, $5(2.3 \%)$ from gastroenterology, and 2 patients (0.9\%) from physical therapy and rehabilitation clinics. Surgical services other than general surgery did not ask for any consultation during the study period.

The main reasons for consultation was nonspecific abdominal pain, with 66 patients (29.9\%). Detailed list of consultation reasons are given in Table 2.

It was found that in 48 cases $(21.7 \%)$ no tests were done prior to consultation, in 38 patients (17.2\%) only blood tests, in 7

Table 1. General surgery consultations according to departments

\begin{tabular}{|lcc|}
\hline Department & $\mathrm{n}$ & $\%$ \\
\hline Internal Medicine & 5 & $2.3 \%$ \\
\hline Gastroenterology & 5 & $2.3 \%$ \\
\hline Physical Therapy and Rehabilitation & 2 & $0.9 \%$ \\
\hline Emergency Department & 203 & $91.9 \%$ \\
\hline Intensive Care Units & 6 & $2.7 \%$ \\
\hline Total & 221 & $100 \%$ \\
\hline
\end{tabular}

cases (3.2\%) only radiological examinations, and in 128 patients (57.9\%) both blood tests and radiological examinations were done prior to surgical consult (Table 3). A detailed classification of the tests suggested in general surgery consultations are given in Table 4, it was seen that additional tests were required in $54.3 \%$ of the patients.

Analyzing completeness of physical examination prior to consultation, the rate of physical examination was the highest rates in criminal cases, while this rate was the lowest in perianal region diseases and bowel obstruction (Table 5).

General surgical consultation resulted in the following recommendations: emergency operation (47), elective surgery (7), general surgery outpatient clinic follow-up (64), no surgical pathology (18), referred to other branches for consultation (41), requirement of further investigations (6), hospital admissions (17), transfer (1), and procedure under local anesthesia (20). Detailed breakdown is shown in Table 6. The details of 47 patients who received emergency surgery and 20 patients re-

Table 2. Reasons for general surgery consultations

\begin{tabular}{|lcc|}
\hline Reason & $\mathrm{n}$ & $\%$ \\
\hline Non-specific abdominal pain & 66 & $29.9 \%$ \\
\hline Nausea and vomitting & 1 & $0.5 \%$ \\
\hline Partial-complete mechanical bowel obstruction & 20 & $9.0 \%$ \\
\hline Incarcarated hernia & 11 & $5.0 \%$ \\
\hline Hemorrhoidal disease & 11 & $5.0 \%$ \\
\hline Gl tract bleeding & 7 & $3.2 \%$ \\
\hline Cholecystitis & 16 & $7.2 \%$ \\
\hline Pancreatitis & 4 & $1.8 \%$ \\
\hline Assault & 1 & $0.5 \%$ \\
\hline Traffic accident & 16 & $7.2 \%$ \\
\hline Stab wound & 4 & $1.8 \%$ \\
\hline Gunshot wound & 2 & $0.9 \%$ \\
\hline Low hemoglobin & 1 & $0.5 \%$ \\
\hline Fall from height & 8 & $3.6 \%$ \\
\hline Perianal pain & 1 & $0.5 \%$ \\
\hline Preoperative evaluation & 19 & $8.6 \%$ \\
\hline Foreign body ingestion & 1 & $0.5 \%$ \\
\hline Colostomy care & 1 & $0.5 \%$ \\
\hline Wound dehiscence & 2 & $0.9 \%$ \\
\hline Areolar drainage & 2 & $0.9 \%$ \\
\hline Postoperative follow-up & 1 & $0.5 \%$ \\
\hline Hollow viscus perforation & 2 & $0.9 \%$ \\
\hline Blunt abdominal trauma & 1 & $0.5 \%$ \\
\hline Diarrhea & 1 & $0.5 \%$ \\
\hline Acute appendicitis & 2 & \\
\hline Pilonidal sinus & 1 & \\
\hline
\end{tabular}


ceiving an emergency intervention under local anesthesia are given in Table 7.

\section{DISCUSSION}

In the last years, both the areas of expertise have increased in number and specific diagnostic and treatment methods in each branch has shown tremendous growth. In patients with multiple diseases, coworking between the the related professionals is inevitable. The scientific help or advice taken from physicians specialized in an area regarding patients is referred as consultation (1-3). In our country, how a consultation should be done is explained in the items $24-30$ of the Medical Ethics Regulation (4). According to this regulation; physicians may want to consult the patient and the patient has the right to request a consultation. During a consultation, discussions and reviews between physicians must be carried in such a way that the patient or his relatives could not hear and understand these. Results of a consultation should be written and signed together, and should be explained to patients by the elderly physicians without disturbing their spirituality. If the consulting physician does not agree with the current treatment, he writes his idea in the consultation paper and may not be involved in the treatment. In case of differences of opinion, if the patient prefers the thoughts of the consultant physician, the primary physician has the right to leave the patient. With

\begin{tabular}{|lcc|}
\hline $\begin{array}{l}\text { Table 3. Test performed prior to general surgery } \\
\text { consultation }\end{array}$ & \\
\hline & Patient number & $\%$ \\
\hline No prior test & 48 & $21.7 \%$ \\
\hline Only laboratory examination & 38 & $17.2 \%$ \\
\hline Only radiologic examination & 7 & $3.2 \%$ \\
\hline Both laboratory and radiologic examination & 128 & $57.9 \%$ \\
\hline Total & 221 & $100 \%$ \\
\hline
\end{tabular}

Table 4. Test performed after general surgery consultation

\begin{tabular}{|lcc|}
\hline Tests & Patient number & $\%$ \\
\hline No tests & 101 & $45.7 \%$ \\
\hline Blood count & 18 & $8.1 \%$ \\
\hline Laboratory tests & 15 & $6.8 \%$ \\
\hline Urine/fecal test & 1 & $0.5 \%$ \\
\hline Ultrasonography (US) & 5 & $2.3 \%$ \\
\hline Computed Tomography (CT) & 5 & $2.3 \%$ \\
\hline Endoscopic tests & 4 & $1.8 \%$ \\
\hline Direct Chest/Abdominal X-ray & 3 & $1.4 \%$ \\
\hline US+Laboratory test & 41 & $18.6 \%$ \\
\hline CT+Laboratory test & 6 & $2.7 \%$ \\
\hline Endoscopy + Laboratory test & 3 & $1.4 \%$ \\
\hline Angiography & 1 & $0.5 \%$ \\
\hline US+CT & 0 & \\
\hline US+CT+Laboratory test & 18 & $8.1 \%$ \\
\hline Total & 221 & $100 \%$ \\
\hline
\end{tabular}

advances in specialization, consultation has been one of the indispensable elements in patient-physician relationship. In complicated cases with difficulty in terms of diagnosis and treatment, more help from experts are being requested or these cases are discussed in meetings composed of experts involved in such cases. Consultation must be given proper attention and should be a part of medical education $(2,5)$. In our hospital, the emergency general surgery consultant physician carries a pager with different signalization according to the degree of urgency of the case, at all times. As soon as the signal appears on the pager, the consultant can obtain patient information from the system, no matter where the patient is and instantly goes by the patient.

In our study group, 92\% of surgical consultations were requested by the emergency service. Emergency service is a separate discipline, led by a specialized team who directed all their energy and information to this subject. The team giv-

Table 5. Physical examination rates prior to general surgery consultation

Reason

Physical Examination prior to consultation

\begin{tabular}{|c|c|c|}
\hline & Yes & No \\
\hline Non-specific abdominal pain & 57 & 9 \\
\hline Nausea and vomitting & 1 & - \\
\hline Partial-complete mechanical bowel obstruction & 6 & 14 \\
\hline Incarcarated hernia & 7 & 4 \\
\hline Hemorrhoidal disease & 3 & 8 \\
\hline Gl tract bleeding & 3 & 4 \\
\hline Cholecystitis & 14 & 2 \\
\hline Pancreatitis & 3 & 1 \\
\hline Assault & - & 1 \\
\hline Traffic accident & 16 & - \\
\hline Stab wound & 4 & - \\
\hline
\end{tabular}

Stab wound

Gunshot wound

2

Low hemoglobin

1

Fall from height

Perianal pain

7

Preoperative evaluation

8

11

Foreign body ingestion

Colostomy care

Wound dehiscence

Areolar drainage

Postoperative follow-up

1

Hollow viscus perforation

Blunt abdominal trauma

Diarrhea

Acute appendicitis

Pilonidal sinus

1

Splenic infarct

1

ITP

1 
Table 6. Decision and suggestions after general surgery consultation

\begin{tabular}{|c|c|c|c|c|c|c|c|c|c|c|}
\hline & 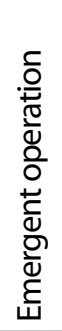 & 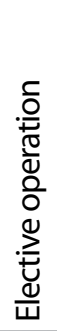 & 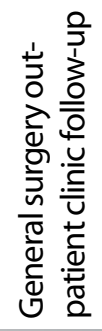 & 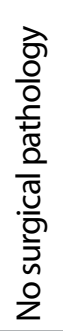 & 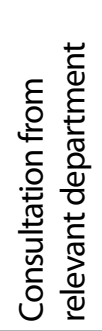 & 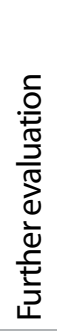 & 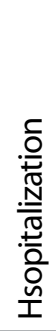 & 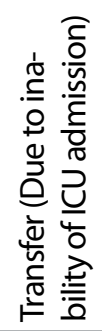 & 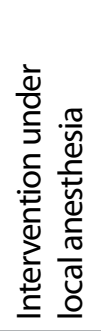 & $\begin{array}{l}\bar{\pi} \\
\stackrel{\mathbb{0}}{\circ}\end{array}$ \\
\hline Non-specific abdominal pain & 24 & 1 & 21 & 5 & 9 & 2 & 3 & 1 & 0 & 66 \\
\hline Nausea and vomitting & 0 & 0 & 1 & 0 & 0 & 0 & 0 & 0 & 0 & 1 \\
\hline Partial-complete mechanical bowel obstruction & 3 & 0 & 5 & 4 & 1 & 1 & 6 & 0 & 0 & 20 \\
\hline Incarcarated hernia & 0 & 5 & 5 & 0 & 1 & 0 & 0 & 0 & 0 & 11 \\
\hline Hemorrhoidal disease & 0 & 0 & 4 & 0 & 1 & 0 & 0 & 0 & 6 & 11 \\
\hline Gl tract bleeding & 0 & 0 & 1 & 0 & 6 & 0 & 0 & 0 & 0 & 7 \\
\hline Cholecystitis & 0 & 0 & 6 & 1 & 4 & 0 & 5 & 0 & 0 & 16 \\
\hline Pancreatitis & 0 & 0 & 1 & 0 & 1 & 0 & 2 & 0 & 0 & 4 \\
\hline Assault & 0 & 0 & 1 & 0 & 0 & 0 & 0 & 0 & 0 & 1 \\
\hline Traffic accident & 0 & 0 & 1 & 4 & 10 & 1 & 0 & 0 & 0 & 16 \\
\hline Stab wound & 3 & 0 & 0 & 0 & 1 & 0 & 0 & 0 & 0 & 4 \\
\hline Gunshot wound & 1 & 0 & 1 & 0 & 0 & 0 & 0 & 0 & 0 & 2 \\
\hline Low hemoglobin & 1 & 0 & 0 & 0 & 0 & 0 & 0 & 0 & 0 & 1 \\
\hline Fall from height & 1 & 0 & 3 & 0 & 4 & 0 & 0 & 0 & 0 & 8 \\
\hline Perianal pain & 0 & 0 & 7 & 2 & 0 & 0 & 0 & 0 & 10 & 19 \\
\hline Preoperative evaluation & 0 & 0 & 0 & 1 & 0 & 0 & 0 & 0 & 0 & 1 \\
\hline Foreign body ingestion & 0 & 0 & 2 & 0 & 0 & 0 & 0 & 0 & 0 & 2 \\
\hline Colostomy care & 0 & 0 & 1 & 0 & 0 & 0 & 0 & 0 & 0 & 1 \\
\hline Wound dehiscence & 0 & 0 & 0 & 0 & 1 & 0 & 1 & 0 & 0 & 2 \\
\hline Areolar drainage & 0 & 0 & 1 & 0 & 0 & 1 & 0 & 0 & 0 & 2 \\
\hline Postoperative follow-up & 0 & 0 & 1 & 1 & 0 & 0 & 0 & 0 & 0 & 2 \\
\hline Hollow viscus perforation & 1 & 0 & 0 & 0 & 0 & 0 & 0 & 0 & 0 & 1 \\
\hline Blunt abdominal trauma & 0 & 0 & 0 & 0 & 0 & 1 & 0 & 0 & 0 & 1 \\
\hline Diarrhea & 0 & 0 & 0 & 0 & 1 & 0 & 0 & 0 & 0 & 1 \\
\hline Acute appendicitis & 13 & 0 & 2 & 0 & 0 & 0 & 0 & 0 & 0 & 15 \\
\hline Pilonidal sinus & 0 & 0 & 0 & 0 & 0 & 0 & 0 & 0 & 4 & 4 \\
\hline Splenic infarct & 0 & 0 & 0 & 0 & 1 & 0 & 0 & 0 & 0 & 1 \\
\hline Idiopathic thrombocytopenic purpura & 0 & 1 & 0 & 0 & 0 & 0 & 0 & 0 & 0 & 1 \\
\hline Total & 47 & 7 & 64 & 18 & 41 & 6 & 17 & 1 & 20 & 221 \\
\hline
\end{tabular}

ing all this service in the emergency department is composed of physicians who have received special training in emergency medicine, or who are in this training (6). The study was conducted in a tertiary referral hospital, that has an emergency medicine department which is officially providing specialty training. However, since the hospital is the designated trauma center for a large province, an average of 1000 patients/day causes a significant burden. Despite the possibility of advanced investigations, it is seen that general surgery consultation is asked in all kinds of many cases irrelevant to surgery. This is not only caused by the excess workload, but also by the new Turkish Penal Code that has strong sanctions particularly in forensic cases. The concept of "having more information in the file, specifically the written note from general surgery, rather than ending up with incomplete work" seems to be adopted. Within the first three months of this study, no surgical pathology was found in or referral to other departments was suggested for $26.7 \%$ of patients.

The most common reason for consultation was abdominal pain with a rate of $29.9 \%$. Acute abdomen is a common presentation of a wide range of complex diseases. Despite advances in technical possibilities a high number of patients still undergoes "diagnostic laparoscopy/laparotomy" with a preliminary diagnosis of "acute abdomen" (7). 
Table 7. Patients who underwent surgical intervention after consultation

Procedures under general anesthesia (Total 47)

\begin{tabular}{|c|c|c|}
\hline - & Acute appendicitis & 28 \\
\hline - & Acute abdomen (other than acute appendicitis) & 14 \\
\hline - & Bowel obstruction & 1 \\
\hline • & Massive gastrointestinal bleeding & 1 \\
\hline - & Intraabdominal bleeding due to fall from height & 1 \\
\hline - & Peptic ulcer perforation & 1 \\
\hline - & Penetrating abdominal trauma & 1 \\
\hline
\end{tabular}

Procedures under local anesthesia (Total 20)

\begin{tabular}{|c|c|c|}
\hline - & Anal abscess & 12 \\
\hline - & Thrombosed hemorrhoidal disease & 6 \\
\hline • & Pilonidal cyst abscess & 2 \\
\hline
\end{tabular}

Gastroenterology department is overtaking especially upper digestive tract bleeding and with the application of endoscopy in both diagnosis and treatment, such patients are no longer consulted to general surgery or they are referred from gastroenterology after diagnosis in the emergency department. There is only one patient who was consulted to general surgery within six months.

When pre-consultation evaluations were examined, we have found that no diagnostic tests were performed in 48 patients (21.7\%) prior to general surgical consultation. No additional tests were required in 101 patients (45.7\%).

When we examine physical examination findings of patients prior to consultation, it was determined that all patients with legal causes like traffic accident, injury, and falling had a complete systematic evaluation that was recorded. For example, in 16 patients with traffic accident, who did not have any abdominal complaint or any pathologic finding and who were hemodynamically stable, general surgery consultations have still been requested. This consultation had to be made to complete the file for medico-legal reasons. Nevertheless, attention should be paid to timing. On the other hand, in perianal region diseases like hemorrhoids, pilonidal sinus, and anal pain the rate of physical examination was only $35 \%$, and the consultation was based only on the grounds of patient complaints. This rate drops to $30 \%$ in cases of bowel obstruction and consultations were based on patient history or the presence of air-fluid levels on abdominal X-rays. The problem in this issue could be related either to the patient or the physician, but anal inspection and digital rectal examination is undoubtedly an important part of physical examination in these patients.

As a result of the consultation, 47 patients (21\%) underwent interventions under general anesthesia, 20 patients (9\%) received minor surgery under local anesthesia, and 7 patients (3\%) were planned for an elective operation.

\section{CONCLUSION}

General surgical consultations have a major impact on patient management. It is evident that with more sub-specialization, multidisciplinary approach in patient management is inevitable. However, looking at the results of surgical consultations, the rate of patients who were found to have surgical disease was $33 \%$, this rate goes up to $62 \%$ if those patients in whom outpatient clinic follow-up is suggested. In a similar 5-month prospective dermatology study on 336 patients, $88 \%$ of the consultations required local treatment, systemic therapy was initiated in 43\%, and treatment was not recommended in $9.2 \%$ (8). In another study from Pulmonary Medicine, 398 consultations were reviewed retrospectively, and it was found that consults were asked for preoperative diagnosis in $31 \%$ and for diagnosis and treatment in $69 \%$ (9). In a similar study from Pulmonary Diseases Department including 338 patients and a 2-year retrospective evaluation, majority of the consultations were from the emergency department with $51 \%$, and in $42 \%$ of them no pathology regarding pulmonary diseases were detected (10). In conclusion, we believe that consultation requests should be asked for in a more selective manner.

Peer-review: Externally peer-reviewed.

Author Contributions: Study concept and design - Ş.K; Acquisition of data - Ş.K., B.I., G.Ö.; Analysis and interpretation of data - O.K.; Preparation of the manuscript - O.K., C.E., H.G.; Statistical analysis - Ş.K.

Conflict of Interest: No conflict of interest was declared by the authors.

Financial Disclosure: The authors declared that this study has received no financial support.

\section{REFERENCES}

1. Ethical code in medicine. Item 19. Türk Tabipler Birliği Yayını, 01.02.1999 (TTB 47. Büyük Kongresi 10-11 Ekim 1998 'de kabul edilmiştir)

2. Güleç S. [Renin inhibition in hypertension]. Turk Kardiyol Dern Ars 2009; 37: 15-22.

3. Lie RK. The ethics of the physician-patient reletionship. Ethical Perspectives 1997; 4: 263-70. [CrossRef]

4. Regulation on Medical Ethics, Items 24-30. Resmi Gazete, Tarih: 19.02.1960 Sayı: 10436.

5. Egnew TR, Wilson HJ. Role modeling the doctor-patient relationship in the clinical curriculum. Family Medicine 2011; 43: 99-104.

6. Regulation on Emergency Medicine Practice. Resmi Gazete. Tarih: 11.05.2000 Sayı: 24046, Değişiklik: 24.03.2004 Sayı: 25412, Değişiklik:15.03.2007 Sayı: 26463.

7. Postier RG, Squires RA. Acute abdomen. In: Townsend CM. Beauchamp RD, Evers BM, Mattox KL, eds. Sabiston Texbook of Surgery. 18th edition, Philadelphia: Saunders Elsevier, 2008: 1180-98.

8. Çiçek D. Evaluation of dermatology consultations. Fırat Tıp Dergisi 2007; 12: 181-3.

9. Öztürk Ö, Ünlü A, Bircan HA, Şahin Ü, Akkaya A. Evaluation of cases with pulmonary medicine consultations. SDÜ Tıp Fak Derg 2005; 12: 27-31.

10. Çobanoğlu U. Evaluation of Pulmonary Medicine consultations in a University Hospital. Tur Toraks Der 2009; 11: 117-21. 